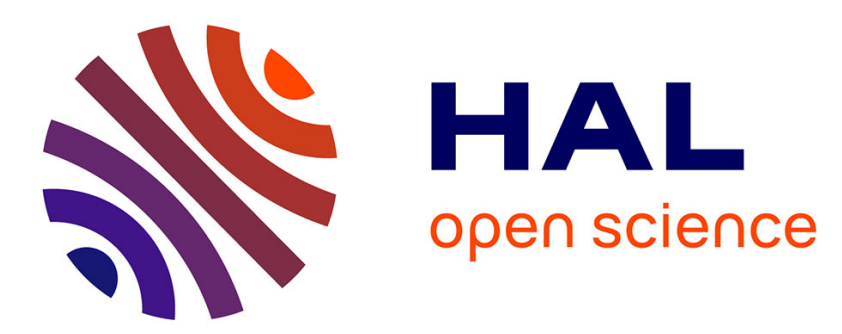

\title{
Operation and control of a dilution refrigerator for spin conversion measurements with neutrons
}

\author{
K. Guckelsberger, H. Friedrich, H. Hennecke, S. Matula, F.H. Mihlan, D. \\ Mugai, R. Scherm
}

\section{- To cite this version:}

K. Guckelsberger, H. Friedrich, H. Hennecke, S. Matula, F.H. Mihlan, et al.. Operation and control of a dilution refrigerator for spin conversion measurements with neutrons. Revue de Physique Appliquée, 1984, 19 (9), pp.779-781. 10.1051/rphysap:01984001909077900 . jpa-00245259

HAL Id: jpa-00245259

https://hal.science/jpa-00245259

Submitted on 1 Jan 1984

HAL is a multi-disciplinary open access archive for the deposit and dissemination of scientific research documents, whether they are published or not. The documents may come from teaching and research institutions in France or abroad, or from public or private research centers.
L'archive ouverte pluridisciplinaire HAL, est destinée au dépôt et à la diffusion de documents scientifiques de niveau recherche, publiés ou non, émanant des établissements d'enseignement et de recherche français ou étrangers, des laboratoires publics ou privés. 


\title{
Operation and control of a dilution refrigerator for spin conversion measurements with neutrons
}

\author{
K. Guckelsberger, H. Friedrich, H. Hennecke, S. Matula, F. H. Mihlan, D. Mugai and R. Scherm \\ Physikalisch-Technische Bundesanstalt, D-3300 Braunschweig, F.R.G.
}

\begin{abstract}
Résumé. - Nous présentons les aspects cryogéniques et opérationnels d'un ensemble expérimental consistant en un cryostat à dilution équipé d'un porte-échantillon multiple, échange-échantillon automatique, alimentation automatisée en cryofluides et un système d'alarme passive. La thermométrie entre $10 \mathrm{mK}$ et $300 \mathrm{~K}$ est décrite ainsi que la lecture et le contrôle de la température à l'aide d'un miniordinateur.
\end{abstract}

Abstract. - We describe the cryogenic and operational aspects of an experiment comprising a dilution refrigerator with a 12-sample container, automatic sample change, automatic refill of cryogenic fluids and a watch-dog alarm system. Thermometry for the range $10 \mathrm{mK}$ to $300 \mathrm{~K}$ is described including computer read-out and computerized temperature control.

\section{Introduction.}

In order to investigate the process of spin conversion we monitor by neutron transmission the time dependent non equilibrium population of tunneling levels in molecular crystals at very low temperatures over extended periods of time [1]. We have built, around a commercial $100 \mu \mathrm{W}$ dilution refrigerator [2], a semiautomatic system satisfying the requirements of the basic physics involved : low temperature, large temperature range $(10 \mathrm{mK}<T<20 \mathrm{~K})$ and long experimental times of up to 6 weeks. To use these long waiting times efficiently, we cool several samples simultaneously in a sample holder taking 12 samples which necessitates a mobile cryostat. A personal computer [3] takes data, changes samples, i.e. moves the cryostat, reads resistance thermometers and changes the temperature of the sample holder as desired. The system runs now largely unattended because automatic refill of cryogenic fluids and a passive alarm system limit intervention of the user to the cooldown procedure and condensation of the mixture. Data are evaluated dayly or weekly off line.

\section{The experiment.}

The dilution refrigerator sits at the end of a neutron guide in the experimental area of the $1 \mathrm{MW}$ research reactor at Braunschweig. A beam of long wavelength $(0.45$ to $1.5 \mathrm{~nm})$ neutrons with $18 \mathrm{~mm}$ diameter is prepared by a velocity selector. Most data are taken at $\lambda=0.93 \mathrm{~nm}$ with a count rate of $1-2 \mathrm{kHz}$ in a ${ }^{3} \mathrm{He}$ detector. The dilution refrigerator is mounted on a commercial drilling machine and can be moved vertically and horizontally. For ease of access during sample mounting, the whole cryostat can be moved horizontally by as much as $80 \mathrm{~cm}$ off the beam axis. During data taking, the automatic sample positioning equipment allows remotely controlled movement (manually and computer-controlled) by $200 \mathrm{~mm}$ horizontally and $400 \mathrm{~mm}$ vertically with a resolution of $0.1 \mathrm{~mm}$ digitally read from a linear potentiometer.

\section{Sample holder.}

A large sample holder $(240 \times 80 \times 10 \mathrm{~mm})$ contains 12 powder samples $(\varnothing 34 \mathrm{~mm}, 4 \mathrm{~mm}$ thick) each mounted in an aluminium sample can. Cells for samples liquid at room temperature are available. It is made from OFHC copper with twelve $0.5 \mathrm{~mm}$ thick windows in its front and back face. Thermal coupling between samples and the copper container is provided by liquid ${ }^{4} \mathrm{He}(1.6 \mathrm{~mol})$ which may be condensed in at temperatures below $4.2 \mathrm{~K}$. The sample holder is fixed in an adjustable way to the mixing chamber. We devised a semiflexible heat contact consisting of two stacks of 128 silver coated lamellae each with dimensions $(60 \times 10 \times 0.2 \mathrm{~mm}$. These stacks are fixed with M3 brass screws to the mixing chamber and sample holder respectively. Total thermal resistance is estimated to be $R \sim 0.8 \mathrm{~T}^{3}(\mathrm{~K} / \mathrm{W})$. This is sufficient for effec- 
tive heat removal $\left(T_{\min } \sim 14 \mathrm{mK}\right)$ while still providing sufficient flexibility to allow for fine adjusment after assembly. At base temperature, the estimated residual heat flux to the sample holder is $\sim 10 \mathrm{nW}$ from three principal sources : (i) residual gas heat load (we found the inner aluminium heat shield fixed at the still at about $1.2 \mathrm{~K}$ ). (ii) Sample $\mathrm{He}$ filling line estimated at well below $1 \mathrm{nW}$ from geometric constraints. (iii) Vibrational heating due to the particular cryostat mounting chosen. Upon moving the cryostat at base temperature with $0.3 \mathrm{~mm} \mathrm{~s}^{-1}$ in any direction the temperature rises only by a fraction of a $\mathrm{mK}$ (Fig. 1) corresponding to a heat input of $\lesssim 50 \mathrm{nW}$ into the sample. In summary, a base temperature of $14 \mathrm{mK}$ for a fully mobile dilution refrigerator seems quite satisfactory.

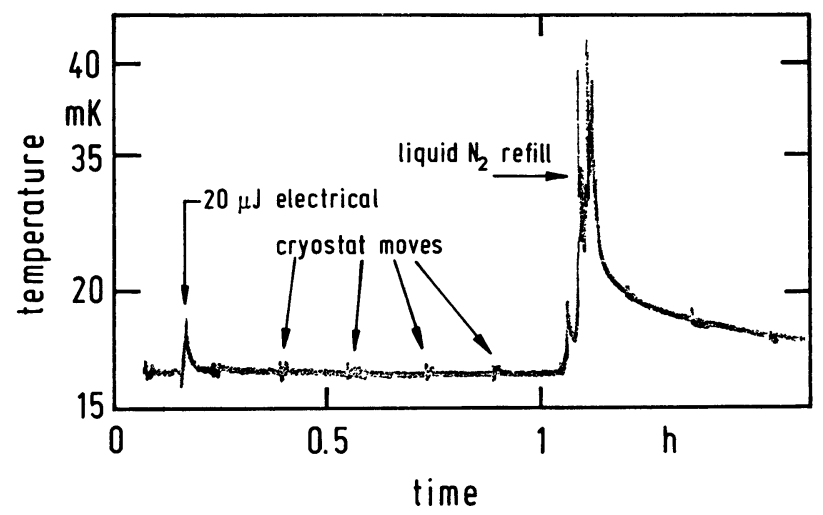

Fig. 1. - Strip chart recording of the base temperature during a typical run. Moving the cryostat by $36 \mathrm{~mm}$ during 100 seconds perturbs the temperature well below $1 \mathrm{mK}$ in contrast to automatic $\mathrm{N}_{2}$ refill which must be improved.

\section{Thermometry.}

Refrigerator performance is monitored with four Speer resistors (at bath temperature, at the $1.5 \mathrm{~K}$ pot the still and the film burner) via a $10 \mu \mathrm{A}$ constant current source and a digital volt meter. For thermometry we use a total of 8 resistance thermometers to cover the full range between $10 \mathrm{mK}$ and room temperature. This poses no problems due to the large sample holder and is convenient because of redundancy and appropriate sensitivity available at all temperatures. Between $300 \mathrm{~K}$ and $30 \mathrm{~K}$ a Pt 100 resistor is used and between $40 \mathrm{~K}$ and $0.6 \mathrm{~K}(30 \mathrm{~K}$ and $1.5 \mathrm{~K})$ two Ge resistors [4] are available. Below $1 \mathrm{~K}$ we have one $\mathrm{Ge}$ resistor $(0.05 \mathrm{~K}<T<6 \mathrm{~K})$ [4] two Speer resistors $(0.01 \mathrm{~K}<T<1.2 \mathrm{~K})$ [5] and two Matsushita $47 \Omega$ thermometers [6]; one of the latter is mounted inside the sample holder to monitor the liquid He temperature. Carbon resistors and especially the Matsushita resistors are known to drift occasionally [7]. Thus, redundancy is important. In addition, two superconducting fixed point devices [8] and a ${ }^{60} \mathrm{Co}$ in hcp Co single crystal nuclear orientation thermometer are permanently installed for thermometric purposes.
Resistances are measured with two independent automatic resistance bridges [9] and a home made distributor allows for easy comparison of any two thermometers. Overall agreement between any pair of thermometers is usually better than $5 \%$ or a few millikelvins. An automatic temperature controller [10] completes the system. Careful double shielding and avoidance of ground loops are essential, electric noise into the thermometer is believed to be well below the $1 \mathrm{pW}$ level. The whole thermometric system may be run manually but is mostly managed by a personal computer.

\section{Computer control.}

We use a CBM 4032 personal computer with a CBM 4022 printer and a CMB 4040 Floppy disk drive for mass storage [3]. It is interfaced to the experiment via an I/O device developed at PTB [11]. It contains 5 scalers. For neutron counting, selector frequency control (i.e. n-wavelength) NO thermometer, etc. The two resistance bridges are read via optocouplers; their set points may be controlled with a special unit described elsewhere [12]. The power range control of the S.H.E. temperature control is selected according to the power required for a given temperature via another unit [12].

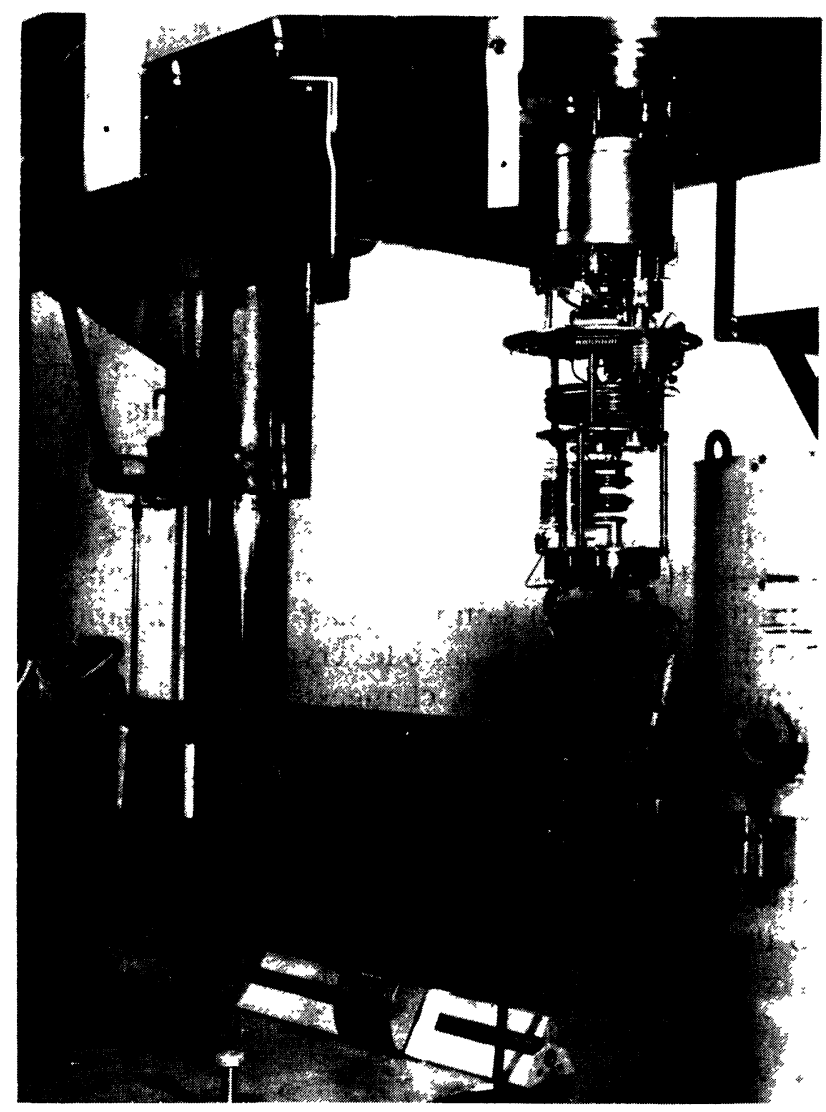

Fig. 2. - Photograph of dilution unit and the sample can. Also visible the pinhole and monitor defining the neutron beam and the detector shield. The column in the background is part of a drilling machine which allows to position the cryostat automatically. 
Two motor control and position sensing devices allow interactive sample change. The whole system is completed by beam control units : wavelength selection via a DAC output driving the analog selector drive unit and intensity control via pneumatic actuators which move neutron attenuators into the beam. A number of fairly large $(24 \mathrm{~K})$ BASIC programs allow, in dialogue mode, to run the experiment flexibly for any sequence of sample, temperature and neutron wavelength. The system has performed reliably for more than one year.

\section{Automatic cryogenics refill and alarm system}

After manual cool-down operator intervention is limited to temperature changes between the two operating regimes $T<1 \mathrm{~K}$ and $T>1 \mathrm{~K}$. In the latter the system runs reliably with the $1 \mathrm{~K}$ pot cooled by gas and some $20-100 \mathrm{mb}$ gas mixture in the dilution circuit.

Cold traps in the return line are placed in a $5011 \mathrm{~N}_{2}$ long time storage vessel topped up once a week. The nitrogen jacket is refilled about every 12 hours, its level being sensed with PT100 resistors and a filling timer may be set for up to 9 minutes. Liquid He refill uses the superconducting level meter provided by Oxford Instruments. At $20 \%$ bath level, a small pump pressurizes the $1 \mathrm{He}$ storage vessel gently with warm He gas at a rate of $91 / \mathrm{min}$. When the $80 \%$ level mark is reached the pump is switched off and a magnetic valve reconnects the vessel to the return line. We have found that automatic refill does not increase the total $1 \mathrm{He}$ consumption : the additional coolant loss due to the permanently installed syphon is about balanced by the coolant loss occurring while cooling a warm syphon once a day during manual transfer.

During unattended operation over long periods a " watch dog " monitors essential parameters as operation of pumps, coolant, cryogenic levels, critical pressures. Any malfunction sets an alarm which is immediately telephoned to the experimenter.

\section{References}

[1] Friedrich, H. et al., J. Phys. C 14 (1981) L-147.

[2] Purchased from Oxford Instruments, Oxford UK.

[3] Purchased from Commodore $\mathrm{GmbH}$, Frankfurt.

[4] GR 200 B AND GR 200 A, Lake Shore Cryotronics, Ohio, USA.

[5] One $0.1 \mathrm{~mm}$ thick provided by Neumaier, K., Garching, another at the mixing chamber provided by Oxford Instruments.

[6] Provided by Godfrin, H., CNRS, CRTBT, Grenoble.
[7] GoDFrin, H., personal comm.

[8] SRM 767 and SMR 768 purchased from NBS, USA.

[9] AVS 45 purchased from RV Elektronikka Oy, Helsinki.

[10] A.T.C. from S.H.E. San Diego.

[11] SCHUSTER, H. et al. report PTB-FMRB-91 (1982), now commercially available as CBM 4072 from Commodore.

[12] Mugai, D. and Guckelsberger, K., to be published. 